in the machine and drawn through the die, the drawing occupying some five minutes. The bars jssued from the die with a surface finer than can be obtained at present by any known mechanical means, except continued friction, and infinitely truer than any turning-lathe produces. It would take a man at a lathe two days at least to turn these bars, and he would then produce inferior results to those obtained in perhaps a quarter of an hour, if the time employed to fix and unfix the bars in the hydraulic drawing bench be included. It will scarcely be necessary to remark, in conclusion, that should this machine fulfil the expectations of the inventor, it will cause a complete revolution in the manufacture of gun-barrels, hollow shafting, axles, piston-rods, and such-like articles.

\title{
To make an Absolutely Correct Camera copy of a Chart by Means of a
} Single I'istorting Lens.* By RoberT H. Bow, C. E.

From the Lond. Cir. king. and Arch. Jour, December, 1863.

I have already mentioned before this society that distortion in a negative may be corrected in the positive taken from it by the camera, whether the distortion arises from the defects of the lens, or from the camera not having been placed squarely to the object in taking the negative. 'This short paper is merely to call attention to a very' simple practical application of the method of correcting that distortion wtich arises from the defects of the leris.

I have here a camera with an achromatic plano-convex lens of $4 \frac{1}{2}$ ins. focal length. It produces pictures which, if of moderate size, are free from anything that a casual observer would detect as distortion; but the following table will give you an idea of the real amount thereof. Before you I have laid a negative taken by the same lens, embracing a field of $80^{\circ}$.

Table showing the Distortion of Seale (measured in the direction of a diameter of the picture) when a distant $\uparrow$ view is taken with the plano-convex achromatic lens of four and a half inches foeal length, described at page 241 of the current volume of The Civil Engineer and Arehitect's. Jonrwal, the stop being three-quarters of an inch from the flat side. (The points in the image corresponding with the pencils at the several angles of obliguity, are obtained by the method referred to in ray paper on the "Curvatures of the Image.")

\begin{tabular}{|c|c|c|c|}
\hline & & $\begin{array}{c}\text { Intervals measured } \\
\text { (approximately) from } \\
\text { the actual image. }\end{array}$ & $\begin{array}{l}\text { Intervals according to } \\
\text { calculation when there } \\
\text { is no distortion. }\end{array}$ \\
\hline Between & rays at $0^{\circ}$ and $5^{\circ}$ & 100 & $100 \cdot 00$ \\
\hline 46 & $\therefore \quad 5^{\circ} \quad \because 110^{\circ}$ & 101 & $101 \cdot 54$ \\
\hline « & $\therefore \quad 10^{\circ} \because 15^{\circ}$ & 102 & $104 \cdot 73$ \\
\hline 6 & " $15^{\circ} " 21^{\circ}$ & $10 \%$ & $109 \cdot 75$ \\
\hline " & " $20^{\circ} \quad$ " $25^{\circ}$ & 105 & $116 \cdot 97$ \\
\hline “ & $\because 31^{\circ}$ & 107 & $126 \cdot 93$ \\
\hline " & $30^{\circ} " 285^{\circ}$ & 110 & $140 \cdot 42$ \\
\hline
\end{tabular}

From this table it appears, then, that an object lying between $30^{\circ}$ and $35^{\circ}$ of obliquity will suffer a contraction from $140 \cdot 42$ to 110 , or a diminution of $30 \cdot 42$ upon a length of $140 \cdot 42$, which is equivalent to

* Read at a meeting of the Edinburgh Photographic Society, 21st October, 1863.

$\dagger$ When the object is not so distunt, the distortion will be somewhat greater. 
21.7 per cent. as compared with the size it would appear if seen lying within the $5^{\circ}$ of obliquity. Of course this is an extreme obliquity, but it is the accompanying distortion which chiefly interferes with our using such an angle, as it may be observed that the negative exhibited is sufficiently sharp for many purposes up to that extent, or for a field embracing $70^{\circ}$.

Between the obliquities of $20^{\circ}$ and $25^{\circ}$ the distortion is equivalent to a contraction of 117 into 105 , or a reduction of 12 on a length of 117, which amounts to a diminution of $10 \cdot 3$ per cent. compared with the scale at the central intervals. Now cven this will be allowed by all tis be serious; for it is as though a foot measure, given correctly near the centre, measured only 10.8 inches near the side of the picture.

Let us now proceed to explain the method of copying without any distortion, whatever the field embraced:-

In the figures let $O$ represent the object or chart, $P$ the photograph, and $c$ the lens - the line beside $c$ indicating the position of the stop.

In Fig. $1, P$ represents the negative first obtained with the stop, arranged as usual for views, and $P$ will therefore be "barrelled." In Fig. 2, if the chart were placed at $O$, we should get a distorted negative $P$ of the "pincushion" order. But if instead of a straight object $O$, in Fig. 2, we place the barrelled negative $P$, as in Figr. 3, we get a copy at $P$, free from all distortion, if made of the same size as $O$, since the tendency of the arrangement to produce pincushioning then Fig. 1.
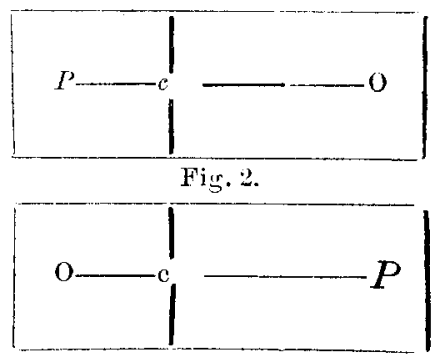
Fig. 3. just suffices to correct the barrelling. In fact each pencil of light is sent back from the negative $P$, in Fig. 3 , to the final sopy $P$, in exactly the same course as that by which it arrived in the first instance from 0 , in Fig. 1 (except in so far as the focussing may be defective.)

This absolutely perfect correction of the distortion only takes place when the final copy is made of the same size with the original chart. But practically, if no great difference exists between the lengths of $P c$ in Figs. 1 and 3 , the correction may be assumed as sufficiently perfect; and in order that these distances may not vary much, we should make our negative considerably less than the final copy to be made from it, when the final copy is to differ much in scale from the chart.

If the negative be made of intermediate size between the chart and the final copy, and the latter be taken with the stop on its side of the lene, the correction of the barrelling will be overdone, so that the final copy will be slightly pincushioned, but generally so slightly that this mode of proceeding will frequently be preferred when a very sharp result is desired.

Vol. XLVII.-TuIRd Series.-No. 6._JUNe, 1864. 
If it be desired that the final photograph $\mathrm{P}$, in Fig. 3, should be a negative, we may effect this by substituting for $P$ a transparency printed from the first negative by superposition.

\section{Coal and Iron in France and other Countries.}

From the Journal of the Society of Arts, No. 590.

A work on property in minerals, by M. Edouard Dalloz, was presented a few days since to the Academy of Moral and Political Sciences of Paris, by M. Wolowski, who read a report on the book in question and on various matters connected with the subject on which it treated. M. Dalloz treats especially of mineral legislation in France and Belgium, but touches incidentally on that of other nations, and also upon the statistics and economy of the mineral question in general, its bearings and influences. In connexion with the statistical portion of the question, M. Wolowski was able to avail himself of more recent records than those used by M. Dalloz, and made an elaborate report to the Academy, from which the following is extracted:-In 1789 France used only half a million tons of coal a year, and of this little more than one-half was raised athome; but in 1830 the production had grown to $1,800,000$, and the quantity imported to 600,000 tons. The progress made since that time is as follows:-

$\begin{array}{cccc} & \begin{array}{c}\text { Production. } \\ \text { Tons. }\end{array} & \begin{array}{c}\text { Importation. } \\ \text { Tons. }\end{array} & \begin{array}{c}\text { Consumption. } \\ \text { Tons. }\end{array} \\ 1835, & 2,600,000 & 800,000 & 3,300,000 \\ 1840, & 8,000,000 & 1,290,000 & 4,290,000 \\ 1845, & 4,000,000 & 2,200,000 & 6,200,000 \\ 1847, & 5,400,0100 & 2,500,000 & 7,600,000\end{array}$

During the four following years political events stopped the growth, both of production and consumption; the quantity raised in France fell back to four millions of tons, and the imports to little more than two millions. Since 1852 the progress was great and constant-

$\begin{array}{lllr}1858, & 5,900,000 & 3,500,000 & 9,400,000 \\ 1854, & 6,000,000 & 4,000,000 & 10,000,000 \\ 1855, & 7,400,000 & 5,000,000 & 12,400,000 \\ 1856, & 7,900,000 & 5,000,000 & 12,900,000 \\ 1857, & 7,900,000 & 5,195,000 & 13,095,000 \\ 1858, & 7,353,000 & 4,840,000 & 12,200,000 \\ 1859, & 7,483,000 & 4,900,000 & 12,400,000\end{array}$

In 1860 came the change in the tariff, and the following are the results to the present time:-

$\begin{array}{rrlr}1860, & 8,391,000 & 5,200,000 & 13,600,000 \\ 1861, & 8,400,000 & 5,300,000 & 13,700,000 \\ 1862, & 9,400,000 & 5,200,000 & 14,600,000 \\ 1863, & 10,000,000 & 5,200,000 \text { more than } 15,000,000\end{array}$

The return forlast year being an approximate estimate made by the Imperial Administration of Mines. By these figures it will be seen that France raises for herself at present as much as she consumed in the whole of 1854 ; and that the consumption itself has doubled since 1847 . It will be observed also, a fact not noted in the report, that since 1860 